\title{
MAKING SENSE OF RESEARCH: UNIVERSITY STUDENTS' DIFFICULTIES IN WRITING ACADEMIC SUMMARIES
}

\author{
Irina Ivanova ${ }^{1}$
}

\begin{abstract}
Reading and understanding authentic research is a fundamental skill in preparing MA students for writing academic essays, exam papers and MA theses. However, if they have not mastered the simpler skills of summarising, less demanding in terms of content and structure texts, it would be more difficult for them to work with academic discourse characterised by higher information density and complex reasoning and argumentation. The paper deals with some problems MA students experience in understanding academic research articles in English and summarising their main points. The analysis of students' summaries reveals problems related to differentiating between essential and less significant information, making sense of empirical data, understanding author's ideas and implications. Students experienced difficulties in referencing, paraphrasing, reformulating and reducing the text in the summary. The findings of the study could be used for improving instruction to target identified issues.
\end{abstract}

Key words: summary, research, academic, MA students, problems

\section{Introduction}

The modernisation of higher education in Bulgaria and the strive to follow practices and standards established in leading EU and US universities puts pressure on educators to prepare students to work with research literature beyond university coursebooks and instruction manuals. One of the main requirements in studying towards a post-graduate degree, such as MA, is for students to be able to look for, select, evaluate and utilise information found in peer-reviewed academic journals and other authoritative sources which publish research, so that they can build on them and ultimately make their own contributions to different research areas.

Making sense of research in the context of higher education is an ability which is often conceptualised as part of a more general idea of students becoming academically literate. This involves mastering a battery of micro-skills or abilities, such as: recognising the genre of the texts used in the respective academic field, deciding on their status, appropriateness and credibility,

1. Associate Professor, PhD, Department of English Studies, Shumen University, Bulgaria, e-mail: irina.ivanova@shu.bg, ORCID: 0000-0002-0216-7061 
identifying textual features which indicate the scope and focus of a text, and utilising the texts for the purposes of assigned academic tasks.

Conceivably, most of the difficulties experienced by novice users of academic discourse stem from a variety of challenges they have in reading and understanding academic texts. These challenges could be explained with the use of inappropriate approaches and strategies in reading, which make students textdependent, submissive readers, focused mainly on retrieving and understanding information, who are unable to use texts to answer their own research questions (see Alexander et al., 2008). Dominant readers, on the other hand, approach a text in a purposeful, focused and flexible manner, extracting the gist while at the same time selecting only the necessary information for further closer scanning. While it is desirable to speed up the process of becoming a dominant reader, there are a number of factors and individual variables, which have to be taken into account, such as students' overall language proficiency and previous educational experience.

Another major source of problems in summarising is the nature of academic writing with its strict genre requirements and features, which a majority of university students in Bulgaria have not encountered in their previous writing experiences. A lot of writing activities which aim at increasing students' ability to generate texts in the target language, are mainly concerned with manipulating language forms, as for example in keyword transformations or exercises for paraphrasing meaning. However, as evidence suggests, excessive use of such tasks might lead to unnatural usages closer to students' mother tongue models, or closer to other familiar non-academic models.

Therefore, the aim of the present study is to analyse samples of students' summary writing in order to identify some of the most common difficulties and look for possible explanations and ways of scaffolding postgraduate students' work with research literature.

\section{Previous research in the field}

There is extensive research on various aspects of academic reading and writing within the fields of English for academic purposes (EAP), English for Specific purposes (ESP) and English as a medium of instruction (EMI), which focuses on ways to assist students in mastering the main genres of academic discourse. Genre-based pedagogy, which relies on "theoretically robust, linguistically informed, and research-grounded text descriptions" (Hyland, 2007), suggests a set of underlying principles to be followed when learning to write. These principles present the process of learning to write as social, needs oriented, requiring explicit outcomes and expectations, which, most importantly, involves learning to use the language. The latter suggests explicit attention to 
the way grammar and vocabulary choices in texts create meanings in different contexts of use. Within the genre-based approach, as viewed by the proponents of the Systemic Functional Linguistics, students' attention is focused on either broad rhetorical patterns called elemental genres, such as narratives, recounts, arguments, and expositions, or on more complex macro genres, such as lab reports, instruction manuals, recipes or editorials (Martin, 1992). In the context of ESP, genres are thought to "structure the roles of individuals within wider frameworks and further assist those individuals with the actualisation of their communicative plans and purposes" (Swales, 1998, p. 20).

Although mastering the genre of the summary is considered essential in developing students' academic literacy, the idea of getting students to summarise whole texts, research articles or larger pieces of academic writing, is sometimes questioned and thought to be counterproductive. It is only considered useful as long as it helps students digest and reduce the source text for further use. Thus, in arguing for students' developing their own voice, and own narrative, Alexander et al. (2008, p. 195) state that "summarising a whole text is equally unhelpful as it does not train students to select the information they need for their own purposes". Swales and Feak (2012) also point out that a good summary should be focused on the aspects of the source text or texts that are relevant as part of some other writing task. While this may be true in working with students who are more academically proficient and capable of formulating their own research questions, there might be a reason for using summary writing as a micro-skill of authentic academic writing, especially in post-graduate studies.

There is not a single unanimous view on what the skill of summarising involves. It might be seen as a source-based writing task, or a reading-to-write task, which relies on students' academic language proficiency for conveying information from reading (Galloway \& Ucelli, 2018; Graham \& Harris, 2017). There is extensive empirical evidence of the dual role that academic language skills play by supporting both text comprehension and text production in writing summaries ((Fitzgerald \& Shanahan, 2000; Shanahan, 2016). The role of Core Academic Language Skills (CALS) in summarising is explored in a series of research publications by Uccelli et al. (2014), Phillips, Galloway and Uccelli (2019), who emphasise the importance of skills such as: unpacking and packing dense information (complex word- and sentence-level structures used to facilitate concise communication); connecting ideas logically (discourse markers that signal to readers how ideas and concepts are related in academic texts); tracking participants and ideas (using varied language when referring to the same participant, theme or idea across a text); organising analytic texts (identifying thesis, argument, counterargument, conclusion); understanding and expressing precise meanings (to achieve communicative clarity); understanding and expressing writer's viewpoint; and recognizing academic language as different from colloquial language. Summarising is often discussed in close 
relation with paraphrasing, as they are usually used together in academic writing to avoid plagiarism by reducing and condensing lengthy souces and changing the wording of a text without changing the meaning (Bailey, 2015). Creating a summary can basically be seen as changing the original text not only in terms of its length and amount of information, but also as a deeper level transformation of a source text into a new text with its own idiosyncrasies, while retaining the gist of the original meaning (Alexander et al., 2008; Hyland, 2007).

As a key skill in writing larger pieces of research, such as reports, literature reviews or research articles or dissertations, summarising is addressed in almost all coursebooks and instruction manuals on academic writing. However, there is no consensus as to what types of texts are to be summarised. The source texts can range from shorter texts on specific subject-related topics, to highly complex research papers, in which authors refer to a large number of academic sources, which increases their intertextuality. The latter are much more demanding for students and are used in EAP courses for post-graduates with the aim of preparing their transformation from consumers of research-based knowledge to creators of such knowledge (Hood, 2005, 2008). Such texts require a much higher level of academic language proficiency, which additionally increases the level of task difficulty for non-native speakers.

Due to a broadly defined nature of summarising, research differs in the ways of conceptualising the processes involved in creating a summary. Some researchers are more interested in students' perceived difficulties on the basis of surveys and interviews (e.g. Habibi et al., 2017; Lin \& Maarof, 2013), while other identify issues and challenges based on studying the process of mastering techniques in drafting summaries, such as paraphrasing (e.g. Choy \& Lee, 2012; Keck, 2006), or creating the end products - the summaries submitted for evaluation (Hyland, 2007; Sung et al., 2016). In relation to the latter, there have been attempts to facilitate the process of evaluation by creating automatic summary assessment and feedback systems based on latent semantic analysis (LSA) (see Landauer, Foltz \& Laham, 1998; Wade-Stein \& Kintsch, 2004). Built on these principles, the web-based tool Write to Learn provides learners with feedback based on the assessment of key elements of summary writing such as content, length, amount of copied text in comparison to the original, spelling, redundancy, and relevance. These elements could be used as criteria for assessing students' summaries, while at the same time identifying their strengths and weaknesses to be addressed in further instruction and corrective feedback. Some assessment frameworks are focused on content, language or efficiency-related difficulties in writing (Rivard, 2001), while other assessment schemes rely on comparing students' summaries with the source text, coding each sentence in the summary according to the amount the subsumed source text, and the quality of paraphrase or integration (Friend, 2001). 
The research on students' difficulties in summary writing takes into consideration the context of EAP instruction and identifies a number of variables, such as students' language and academic proficiency, academic field, social and cultural educational background, and previous experience in writing. An important variable relevant to the present discussion is the students' status as non-native speakers of English, which is thought to affect their achievement in a negative way, due to a tendency to copy from the source text, or use inappropriate source borrowing or substitution strategies (Campbell, 1990; Kim, 2001; Pecorari, 2003; Shi, 2004). Similar problems, assigned to students' language competence in English were discussed in a study of Bulgarian doctoral students' executive summaries by Doykova (2017), who identified difficulties at text organisation level, varying from lack of framework to unbalanced structure, inadequate presentation of methodology, and direct borrowing from the source text. In a study of the role of strategies in the summary writing of Taiwanese undergraduates, Yang (2014) found out that in the interplay of constructive reading and writing processes, the role of cognituive strategies, such as organising, selecting, connecting, paraphrasing, and quoting is as important as the use of metacognitive strategies, such as planning and evaluating. Researching Bulgarian undergraduates' reading abilities, Gerova (2019) identified age and experience as the two factors which have a decisive role in the use of metacognitive strategies. While metacognitive strategies are triggered automatically and subconsciously as part of students' normal reading and writing strategies (Johns, 1985), they can also be "triggered through teacher modeling, revision, checklists, and guidelines with metacognitive cues built in" (Kirkland \& Sauders, 1991, p. 114). These findings confirm the importance of strategic instruction in academic writing in general and in summary writing in particular.

\section{Research Questions}

There are three main questions which this study aims to address:

1. What are the main difficulties Bulgarian post-graduate students experience in writing academic summaries?

2. Are the difficulties related mainly to understanding the source text or do they stem from insufficient command of the target genre features?

3. Can students' difficulties be traced back to their general language proficiency and their previous educational experience?

\section{The study: participants, methods and materials}

The main method used for the purposes of the present study was textual analysis. 42 summaries of academic articles in the broad field of language 
education and teacher training were collected at the end of a short elective course in academic writing at a Bulgarian state university. The summaries were written as an assignment by MA students of English philology who had opted for a teaching qualification. Each student had to find a research article in the field of teacher training, and submit it together with the summary, so that the summary would be evaluated against its source text. During the course the students were instructed how to look for quality research publications, and were given guidelines about summary length, content and structure. The tasks which aimed to teach students how to write their summaries included: selecting appropriate source texts, reading the text for extracting essential ideas, arranging and linking the ideas, referencing and paraphrasing, reducing the amount of text, utilizing self- and peer correction and multiple drafting. Students were encouraged to use multiple instruction manuals and online guides produced by British and American Universities. In class, students analysed sample materials and did mini tasks of summarising parts of research articles before writing summaries of whole articles. They were given instructions which guided their way and focused their attention through reading the source article, highlighting the mains signposts and then making notes and drafting the summary. The learning processes required parallel close reading and note taking, resulting in drafting. They followed the logic of reading-to-writing tasks and included:

Focus on reading:

- working with the article abstract and extracting the meaning behind its structure; comparing informative and not very informative and wellstructured abstracts;

- focusing on the structure of the research article and its variations; the way article structure is reflected in the abstract; the length and balance of article sections;

- discussion of the introduction and its role in providing a wider view of the research field; narrowing the focus; attention to the main thesis and its significance for academic study;

- analysis of the literature review or theoretical background - assessing the relevance of sources; interrelation between different positions in research; distinguishing between authoritative, seminal works and marginal or smaller-scale research with local contextual relevance;

- understanding the study - hypotheses, research questions, research methodology, participants/ corpus, empirical evidence, case studies, etc.;

- analysing the approaches to data analysis in the source texts;

- making sense of the results, findings, implications and conclusions; 
Focus on writing:

- note-taking while reading - identifying key ideas; paraphrasing and referencing;

- reducing the literature review to a few generalised ideas;

- conveying the research questions, methodology and analysis procedures in a brief informative manner;

- reporting the main results, implications and conclusions.

- reviewing (peer-reviewing) the first draft, correcting and re-drafting, while focusing on the structure and organisation of ideas, paying attention to academic style rather than checking for accuracy alone.

\section{Data Analysis}

In order to identify problematic areas in students' summary writing, the analysis procedure was based on comparing students' summaries with the source texts. The fact that the summaries closely reflected the structure of the originals resulted in variation in their length, structure, and linguistic features, which necessitated a closer attention to the original in evaluating the quality of the generated texts. One advantage of giving students the freedom to select their source texts allowed for identifying a wider range of problems in summarising, compared to the training tasks in which all students worked with the same source text. On the other hand, this made it more difficult to trace common tendencies and come to generalisations about the frequency of occurrence of the same challenges.

The problems were identified as a result of a two-step procedure: first, each summary was compared and assessed against its source, and second, problems, identified in all summaries were compared and generalised to larger categories in order to reduce their dependence on individual source texts. The criteria used in comparing the texts and identifying problems were the same for all summaries irrespective of their source, and included the following:

- content: the extent to which the summary covers the gist of the article and key points of each section of the source text;

- length: whether the summary is an adequate reduction of the original text. For the purposes of the present study, the students were told to limit their summaries to about one fourth of the source article;

- direct borrowing from the source: whether the amount of copied text is too large compared to the original text. Any stretches of text which exceed 4-5 words in a row were considered direct borrowing;

- correct referencing: consistent referring to the author and the source, strictly following the requirements for avoiding plagiarism;

- avoidance of personal interpretation, opinion and commentary; 
- redundancy and irrelevance: presence of repeated or unrelated ideas in the summary;

- coherence and cohesion of the summary text;

- lexical and grammatical range and correctness;

- spelling and punctuation.

The set of criteria was designed having in mind considerations of validity and reliability to ensure consistency in evaluating the summary irrespective of the source text chosen by the students. The criteria are more detailed than the analytic descriptors usually used for assessing writing, such as task achievement, text structure and organisation, cohesion and coherence, lexical and grammatical range, and accuracy, which are linked to standards and grades. The role of criteria in the present study was more to structure the analysis and identify key issues, than to formally assess students' performance.

\section{Results and discussion}

The detailed analysis of students' summaries made it possible to identify a number of issues related to the criteria described in the previous section of this article. Working with criteria makes it is possible to recognise problematic issues as deviations from an approximate standard set by criteria. In the discussion below the most symptomatic deviations are exemplified through excerpts from students' summaries. Word-limit constraints in the present paper necessitated the illustration of each identified difficulty with a single example of students' writing which is compared to an excerpt from the source text or discussed without such reference, depending on the nature of the problem. The authors of the source texts are indicated in brackets at the end of each excerpt and are in italics to avoid confusion with the other sources in the excerpts. As it is virtually impossible to assign each problem to difficulties related to either reading or writing, the process of summary creation is conceptualised as a continuum with reading and writing at its ends, and the discussion below follows this logic. The issues presented first are more closely related to the content of the summaries and the students' efforts to convey meaning, while the latter ones could be assigned to language-related deficiencies and poor command of academic discourse.

\section{Difficulties related to:}

\section{- understanding the gist of the whole article or of key source segments}

Understanding the gist of a complex piece of academic discourse, such as a research article, requires fast and efficient skimming of the whole text with a special attention paid to the abstract, introduction, main findings and conclusion in order 
to understand the author(s) stance and contribution to the topic at hand. In the following sentence from an article on action research and reflective practice, the student failed to understand what the authors' position is. The misunderstanding of the central thesis of the research paper led to a summary which lacks focus and greatly compromises the meaning of the source. The reduced sentence distorts the original meaning due to the student's inability to correctly interpret the complex sentence and the meaning of the cohesive devices:

\begin{tabular}{|c|c|}
\hline source & summary \\
\hline $\begin{array}{l}\text { Its central thesis is that, although action research has a crit- } \\
\text { ical role to play not least as a means of } \\
\text { building the capacity of teachers as researchers of their } \\
\text { own practice, there has been insufficient attention given } \\
\text { to both the nature of reflection in the action research pro- } \\
\text { cess, and its relationship to the purposes, processes and } \\
\text { outcomes. (Leitch \& Day, 2000, p.179) }\end{array}$ & $\begin{array}{l}\text { The central thesis of the } \\
\text { authors is that action re- } \\
\text { search is not sufficient } \\
\text { to understand reflection } \\
\text { and its links to aims, pro- } \\
\text { cesses and results. }\end{array}$ \\
\hline
\end{tabular}

\section{- summarising ideas without understanding them in depth and detail}

This is a problem typically associated with students' difficulties in scanning a text and identifying specific information. It might also result from poor understanding of the author's logic and the discourse flow, or from language deficiencies which impair understanding. In the case below important details are omitted which disrupts the logic of the source and leads to reduction and simplification of the original meaning. The idea of decontextualisation and abstraction of knowledge to make it generalisable and transferrable is much simplified in the summary text.

\begin{tabular}{|c|c|}
\hline source & summary \\
\hline $\begin{array}{l}\text { The process-product paradigm (Dunkin \& Biddle, 1974), } \\
\text { which is more commonly known as "knowledge transmis- } \\
\text { sion", finds its historical and theoretical roots in cognitive } \\
\text { learning theories. These theories have defined learning as } \\
\text { an internal psychological process isolated in the mind of } \\
\text { the learner as an individual, and largely free from the social } \\
\text { and physical contexts within which it occurs (Lenneberg, } \\
\text { 1967). Learned ideas are transported from one place to an- } \\
\text { other. For this reason, this paradigm has focused on notions } \\
\text { of transfer in learning to probe how knowledge } \\
\text { travels from one setting or context to another. It has thus } \\
\text { tended to see classrooms and formal schooling as "a site } \\
\text { for decontextualized knowledge so that, abstracted, such } \\
\text { knowledge may become general and hence generalizable, } \\
\text { thus transferable to situations of use in the 'real' world" } \\
\text { (Lave, 1997, p. 18). }\end{array}$ & $\begin{array}{l}\text { The process-product par- } \\
\text { adigm, also known as } \\
\text { knowledge transmission, } \\
\text { is a cognitive learning } \\
\text { theory which states that } \\
\text { ideas are transferred from } \\
\text { one place to another. In } \\
\text { the classroom knowledge } \\
\text { is decontextualised in or- } \\
\text { der to be transferred to } \\
\text { the real world. }\end{array}$ \\
\hline
\end{tabular}




\section{- unacknowledged authors, references and sources}

This is one of the most frequent problems in students' summaries, a typical case of plagiarism, when the student fails to refer to the source used, as in the example below where both the author of the article and the source cited are not acknowledged. Moreover, the author's personal stance is presented as the student's personal opinion, which itself is inappropriate in a summary.

\begin{tabular}{|l|l|}
\hline source & summary \\
\hline I now believe that professional educators may have under- & I think that educators un- \\
estimated the complexity of Schön's (1983) contribution to & derestimate the nature of \\
how we think about the nature of professional learning. & professional learning and \\
Fostering reflective practice requires far more than telling & simply tell people to re- \\
people to reflect and then simply hoping for the best. (Rus- & flect without explaining \\
sel, 2005, p. 203) & how to do it. \\
\hline
\end{tabular}

\section{- failure to distinguish the voice of the author(s) of the article from the researchers whose work they cited}

Another issue in the summaries is related to referring to multiple 'voices' in research, such as the article's author(s) and the sources they use to support their arguments. In the example below by 'the authors' the student understands both the authors of the article (Johnson and Freeman) and the other researchers mentioned by them.

\begin{tabular}{|c|c|}
\hline source & summary \\
\hline $\begin{array}{l}\text { Drawing from the allied perspectives of socio-cultural the- } \\
\text { ory (Leont'ev, 1978; Vygotsky, 1978) as well as situated } \\
\text { cognition (Chaiklin \& Lave, 1996; Kirshner \& Whitson, } \\
\text { 1997), we contend that how people - in this case teachers } \\
\text { and those who are learning to teach - do what they do is } \\
\text { critical. (Johnson \& Freeman, 2001, p. 61) }\end{array}$ & $\begin{array}{l}\text { The authors claim that it } \\
\text { is very important to know } \\
\text { how teachers do things } \\
\text { (Chaiklin \& Lave, 1996; } \\
\text { Johnson \& Freeman, } \\
\text { 2001; Kirshner \& Whit- } \\
\text { son, 1997; Leont'ev, 1978; } \\
\text { Vygotsky, 1978). }\end{array}$ \\
\hline
\end{tabular}

\section{- indiscriminate acknowledgement of researchers in students' summaries}

In the example below, the student failed to link the ideas to the researchers they belong to, thus failing to acknowledge their contribution to research. This might stem from the wrongful assumption that mentioning all names at the end of a statement is sufficient as an acknowledgement of their contribution. However, while it might be appropriate in literature reviews to simply enlist researchers who wrote on a topic, it is not suitable in clarifying different, often conflicting aspects of a topic when researchers' positions have more complex interrelations. 


\begin{tabular}{|l|l|}
\hline \multicolumn{1}{|c|}{ source } & \multicolumn{1}{|c|}{ summary } \\
\hline According to Schön (1983) reflection-in-action & Thinking accompanies \\
acknowledges the tacit processes of thinking which & doing in the learning pro- \\
accompany doing, and which constantly interact with and & cess. This happens un- \\
modify ongoing practice in such a way that learning takes & consciously and reflec- \\
place. Much of this may remain unconscious, tacit and & tion-in-action leads to re- \\
unverbalised (Clark \& Yinger, 1977), though Loughran & framing and improvising \\
(1996) suggests that, in meeting unanticipated problem & to view the experience in \\
situations, reflection-in-action comprises & a different way (Clark \& \\
reframing the problem and improvising on the spot so that \\
the experience will be viewed differently. (Leitch \& Day, \\
2000, p.180)
\end{tabular}

\section{- failure to understand the interrelation of ideas, common themes and researchers' positions in the literature review section}

Literature review section is one of the most difficult to summarise, mostly due to students' lack of experience in reading and comparing multiple sources on the same topic. Although exam preparation for TOEFL or CPE provide practice in summarizing 2 to 3 sources on a single topic, the majority of study participants lack such experience. An additional difficulty arises when the source text does not contain author's clear and traceable formulation of a personal stance. In the example below Borg's appeal to look beyond what teachers know is misinterpreted as disagreement with previously mentioned authors.

\begin{tabular}{|c|c|}
\hline source & summary \\
\hline $\begin{array}{l}\text { Since the mid 1980's, research in this domain had taken } \\
\text { hold in general educational research in North America. } \\
\text { One well-known example } \\
\text { is the work of Shulman's Knowledge Growth in Teaching } \\
\text { Project (Shulman, 1987), in which he and his colleagues } \\
\text { argue for a distinction } \\
\text { between disciplinary knowledge, which often defines the } \\
\text { subject matter to be taught, and teachers' pedagogical } \\
\text { content knowledge, or how and why teachers teach content } \\
\text { to particular students as they do (e.g. Grossman, 1990). To } \\
\text { understand the activity of teaching and learning in our field } \\
\text { for example, we must look beyond what teachers know or } \\
\text { don't know about grammar to why they teach grammar } \\
\text { as they do (e.g. Borg, 1998). (Johnson \& Freeman, 2001, } \\
\text { p.60) }\end{array}$ & $\begin{array}{l}\text { While Shulman (1987) } \\
\text { and his colleagues ar- } \\
\text { gue for distinction of } \\
\text { disciplinary knowledge } \\
\text { and content knowledge, } \\
\text { Grossman (1990) agrees } \\
\text { with them, but Borg } \\
(1998) \text { disagrees, say- } \\
\text { ing that we must look be- } \\
\text { yond teachers' knowl- } \\
\text { edge about grammar and } \\
\text { the way they teach it. }\end{array}$ \\
\hline
\end{tabular}

\section{- personal judgment and/or interpretation which should not be included in a summary}

One of the issues in the analysed summaries is students' urge to express their personal opinion. Although students were instructed to refrain from expressing 
personal judgment, some were tempted to do so and, what is more, used the ideas in the source text as a reason to state their own position. Frequently this led to oversimplification and distortion of the source author's ideas, as in the example below:

\begin{tabular}{|l|l|}
\hline \multicolumn{1}{|c|}{ source } & \multicolumn{1}{|c|}{ summary } \\
\hline Cooperative Development values intellectual (e.g. & Edge and Attia (2014) \\
information in books) and experiential (e.g. practice & claim that cooperative \\
in classrooms) sources of teacher learning and adds a & development is important \\
third source: learning through speech. In this process of & for teachers' intellectual \\
formulating ideas, articulating thoughts, and expressing & and experiential learn- \\
emotions, teachers may identify new avenues for their & ing. Although it might \\
personal and professional transformation. (Edge \& Attia, & bring about professional \\
2014, p.66) & $\begin{array}{l}\text { transformation, teachers } \\
\text { should be able to identify } \\
\text { their own ways of devel- } \\
\text { opment. }\end{array}$ \\
\hline
\end{tabular}

\section{- lack of caution in expressing ideas; lack of hedging devices}

Lack of caution in presenting ideas is another frequently observed feature the studied summaries. As Vassileva (2001, p. 98) points out, "Bulgarian and especially Bulgarian English show a higher degree of commitment and hence - a lower degree of deference towards the discourse community both in terms of quantity (the overall number of hedges and boosters) and in terms of quality (the degree of commitment and detachment implied in the linguistic means of expression)". When summarizing, students tend to omit hedging devices form the source texts as unimportant, and use fewer indicators of the degrees of certainty such as modal verbs, adverbs of frequency or possibility. In the example below 'will' is substituted for the original 'would', and the verbs 'suggest' and 'believe' which express deference and reduce the degree of commitment are omitted from the summary.

\begin{tabular}{|l|l|}
\hline source & summary \\
\hline The data and their analysis suggest that the participants & The study showed that \\
have an ambivalent feeling about dynamic assessment and & some participants were in \\
its potential application to the English language assessment & favour of dynamic assess- \\
in the UK HE. Some of the lectures were in favour of & ment, as it will give stu- \\
dynamic assessment of the English language skills of & dents' ownership of the \\
HE students. For example, they said this would allow the & course and more chances \\
students to take some ownership by setting the agenda for & to show their abilities, \\
intervention, as it is their course after all. They also said & making the assessment \\
dynamic assessment would avoid giving the students only & less stressful. \\
one chance, which is unfair and which does not provide a & \\
true picture of their abilities. They believed that dynamic & \\
assessment would be less stressful for students. (Nazari, & \\
2017, p. 110). & \\
\hline
\end{tabular}




\section{- close adherence to the source language}

Known also as language borrowing, lifting or straight copying, it results from poor command of the target language in general and academic discourse in particular, as well as from insufficient mastery of text generation skills and strategies, paraphrasing, synonymy, and discourse management. In the example below it can be seen in the similar word order (The author states that..., Little (2003) states that) and the repetition of the same lexemes (autonomy entails).

\begin{tabular}{|l|l|}
\hline \multicolumn{1}{|c|}{ source } & \multicolumn{1}{c|}{ summary } \\
\hline The traditional teacher-driven classroom has become \\
pedagogically limited in making language learning & The author states that the \\
traditional teacher-cen- \\
a student-centered instruction that stresses learners' & tered classroom is lim- \\
capacity to learn autonomously. According to Little & ited in making language \\
(2003), autonomy entails decision-making, critical & learning student-centered \\
reflection and social interaction. Autonomous learners & and autonomous. Little \\
are responsible for their own learning and are actively & (2003) states that autonomy \\
involved in the learning process by setting personal & entails decision-making, \\
goals, planning and executing tasks, and reviewing their & critical reflection and social \\
progress (Dam, 1995; Little, 1996). (Lee 2011, p. 87) & interaction and the learn- \\
& ers are responsible and ac- \\
& tively involved in the learn- \\
& ing process. \\
\hline
\end{tabular}

\section{- excessive or incorrect paraphrasing}

As a rule, paraphrasing is used when students "wish to stay close to the author's idea" (Alexander et al., 2008, p. 195). Excessive paraphrasing results in a superficial change of language elements - usually single words - which makes students' texts sound unnatural while failing to summarise the ideas in the source. In the example below the student substituted 'relabeled' for 'renamed', 'has not been changed' for 'without altering', and 'a bit of preparation' for 'prepared'. Although these changes are good examples of paraphrasing, they do not contribute to compressing the meaning as required in a summary. In the second sentence of the summary the word 'odd' was wrongly changed to 'strange', which distorts the idea of the source text.

\begin{tabular}{|c|c|}
\hline source & summary \\
\hline $\begin{array}{l}\text { In the UK based language school in which I_work, the } \\
\text { teacher training noticeboard has been relabeled teacher } \\
\text { development, although what is posted on the board generally } \\
\text { has not been changed. Teachers are still offered three or } \\
\text { so seminars a term by outside speakers. However, on the } \\
\text { timetable something new has appeared... a development } \\
\text { period for each teacher. In fact it is not new time, but that } \\
\text { odd period that has always been on the timetable when } \\
\text { we used to do a bit of preparation and have tea. (Davies, } \\
\text { 1999) }\end{array}$ & $\begin{array}{l}\text { In the English lan- } \\
\text { guage school in which } \\
\text { Davies (1999) worked } \\
\text { teacher training was re- } \\
\text { named teacher develop- } \\
\text { ment without altering its } \\
\text { meaning. Instead, it was } \\
\text { the old but strange period } \\
\text { when teachers usually } \\
\text { prepared and had tea. }\end{array}$ \\
\hline
\end{tabular}




\section{- use of inappropriate synonyms due to lack of understanding and poor command of collocations and set phrases}

The ability to use synonyms appropriately is part of mastering the skill of paraphrasing. However, students are often unaware of the contextual dependence of synonyms, their genre affiliation and connotation. The example below shows how the superficial use of synonyms, such as 'operate' - 'function', 'in isolation' - 'on their own', and 'complex' - 'complicated' distort the meaning of the original text. In the second sentence of the summary the phrasal verb 'figure out' is confused with the noun 'figures', and the passive form of the verb 'give' is erroneously substituted for the phrase 'given that'. This is an extreme example of how misunderstanding the source due to poor command of the target language can disrupt the logic of the original text and lead to summaries which do not represent the meaning of the source correctly.

\begin{tabular}{|c|c|}
\hline source & summary \\
\hline $\begin{array}{l}\text { However, teachers' practical theories do not operate in } \\
\text { isolation but are sensitive to the ways that the contexts in } \\
\text { which teachers work influence their practices. Simply put, } \\
\text { teachers' practical theories represent the complex ways } \\
\text { in which teachers figure out what to do about a particular } \\
\text { topic, with a particular group of } \\
\text { students, in a particular time and place (Johnson, 1999). } \\
\text { Given this embedded view, how teachers actually use their } \\
\text { knowledge in classrooms } \\
\text { has come to be seen as highly interpretive, socially } \\
\text { negotiated, and continually restructured within the } \\
\text { classrooms and schools where teachers } \\
\text { work. (Johnson \& Freeman, 2001, p.56) }\end{array}$ & $\begin{array}{l}\text { Teachers' practical the- } \\
\text { ories do not function on } \\
\text { their own, but are compli- } \\
\text { cated figures of specific } \\
\text { topics, groups, times and } \\
\text { locations. When given } \\
\text { this imbedded view, they } \\
\text { use their knowledge to } \\
\text { interpret, negotiate and } \\
\text { restructure their work. }\end{array}$ \\
\hline
\end{tabular}

\section{- long, complicated sentences}

The tendency to use long, unnecessarily complicated sentences stems from students' poor understanding of the nature of the English academic discourse, characterised by simplicity, clarity and transparency. While long complex sentences might indeed occur in academic writing (Bailey, 2015), excessive sophistication and complex subordination make the text clumsy and reduces its readability. According to Vassileva, this sophisticated style of writing typical of Bulgarian English academic discourse could be "due to the long-standing impact of French and Russian, while English might be still in the process of gaining such stylistic influence" (see Vassileva, 2001, p. 100). In the example below the student compressed four sentences into one, creating unnecessary confusion without making the sentence more informative. 


\begin{tabular}{|l|l|}
\hline \multicolumn{1}{|c|}{ source } & \multicolumn{1}{c|}{ summary } \\
\hline This article concerns the subject of the professional \\
development of the language teacher. It presents recent \\
descriptions of, and research into, the nature, processes & Mann's state-of-the art \\
and tools of teacher development and language teacher & teacher's development \\
discusses the subject by \\
education. The emphasis here is on what is possible \\
presenting recent descrip- \\
for the individual who wants to grow and develop as a & tions and research of the \\
language teacher. It is mainly concerned with presenting & specifics, processes and \\
the choices language teachers have in continuing 'with & instruments for teacher \\
their professional development as language teachers once & development and educa- \\
their period of formal training is over' (Richards \& Farrell, & tion, and lays emphasis \\
2005, p. 1). (Mann, 2005, p. 103) & on the possibilities ex- \\
& isting for those who de- \\
& sire to grow as a teacher, \\
& by outlining the choices \\
& teachers have after their \\
& training is finished. \\
\hline
\end{tabular}

\section{- difficulties related to students lack of sense of audience or purpose of writing}

The aspect of academic writing which is particularly difficult for students to understand is the idea of writing for an audience with a specific purpose in mind. It is widely accepted that academic texts "communicate ideas about a specific topic to an audience that the writer does not know personally" (Alexander et al., 2008, p. 42). However, the idea of belonging to an academic community has never been stated explicitly in Bulgarian education system, mostly due to the fact that lecturers' requirements for written work differ widely not only within a higher institution but within a faculty or a single department as well. This in turn erodes the idea of audience since the only readers of the students' work are the lecturers whose requirements students try to meet. Furthermore, students often fail to see a genuine purpose for producing a piece of writing, other than assessment of their skills in writing by the lecturer. Since the audience for writing a summary in the context of the present study is an imaginary academic community, whose expectations students find difficult to imagine, the summaries are often characterized by lack of coherence and purpose, and look like a sequence of random ideas.

\section{Conclusion and implications}

The analysis of students' summaries revealed issues with mastering the features of what Johns (1997) calls 'general expository academic prose'. These are key features of academic discourse, such as explicitness, intertextuality, objectivity, emotional neutrality, hedging, correct social relations, appropriate genre requirements, use of metadiscourse and signalling, and the display of a 
'disciplinary vision'. Although most of these features were explicitly highlighted in the course of academic writing, it turned out that brief familiarisation was not sufficient for their mastering.

As in a typical reading-to-writing task, a range of issues were found to stem from students' difficulties related to reading, such as understanding the gist of the whole article and its main components, identifying key details and their significance in the researcher's argumentation. These issues in turn led to problems with acknowledging articles' authors and references in the source texts. Some students failed to distinguish the voice of the authors of the article from those of the researchers whose work they cited. Particularly challenging was to summarise literature review sections - a lot of students misunderstood the interrelation of ideas, common themes and researchers' positions. Another challenge for students was to restrain from personal judgment and interpretation of researchers' ideas in the summary, and the lack of caution in expressing ideas. The resulting high degree of commitment was evident in the omission of hedging devices in students' summaries, a problem which should be targeted and improved through corrective feedback, since hedging is central to scientific argument and, ultimately, to science itself (Hyland, 1998).

Students' difficulties might stem from a lack of experience in writing academic texts, summaries in particular. This means that by the time of submitting their summary for assessment, students might not have been asked to summarise research in other academic disciplines. In this situation they usually adopt a product approach in their writing, i.e. to closely mimic sample texts without having a good understanding of the text's genre features. Our findings support Vassileva's (2001, p. 100) claim that the general lack of training in writing in the educational system of Bulgaria "fosters mainly reproductive writing focusing on the content rather than the structure of the texts". Even students whose general language proficiency is relatively high, as non-native speakers of English, have deeply ingrained cognitive schemata for writing in Bulgarian, which are "extremely difficult to overcome irrespective of the degree of command of the foreign language" (ibid.). However, students whose language proficiency is not high enough, tend to demonstrate close adherence to the source language, and any attempt to deviate from the source leads to excessive or incorrect paraphrasing, inappropriate synonyms, and long, complicated sentences. The analysis of students' summaries revealed difficulties related to a poor sense of audience and purpose of writing, mainly due to the lack of relevant experience in writing for an audience in students' educational experience.

To sum up, students' problems could be explained with insufficient exposure, experience, and practice in reading and writing academic texts. Consistent practice in reading quality research as part of MA students' assignments could possibly provide the necessary exposure to academic discourse. This in turn 
would sensitize students to the key genre features of different academic genres and would ease the instructor's task of raising students' awareness of the way academic texts are organised. One of the possible solutions when working with less academically proficient students is to reduce the scope and difficulty of the tasks while at the same time scaffolding the process of summarizing, starting from the first encounter with the source text to creating the final draft of the summary.

\section{References:}

Alexander, O., Argent, S., \& Spencer, J. (2008). EAP essentials. Reading, UK: Garnet Publishing Ltd.

Bailey, S. (2015). Academic writing. A handbook for international students. Fourth Edition. London \& New York: Routledge.

Doykova, I. (2017). The format of the PhD summary. In foreign languages and the contemporary higher education. Conference Proceedings. VIII International Scientific Conference. (pp. 384 - 390). Varna: Medical University "Prof. Dr. P. Stoyanov".

Fitzgerald, J., \& Shanahan, T. (2000). Reading and writing relations and their development. Educational Psychologist, 35(1), 39-50.

Friend, R. (2001). Effects of strategy instruction on summary writing of college students. Contemporary Educational Psychology, 26, 3/24.

Campbell, C. (1990). Writing with others' words: Using background reading text in academic compositions. In Croll, B. (Ed.). Second language writing, (pp. 211-230). Cambridge: Cambridge University Press.

Choy, S. C., \& Lee, M. Y. (2012). Effects of teaching paraphrasing skills to students learning summary writing in ESL. Journal of Teaching and Learning, 8(2), 77-89.

Gerova, G. (2019). Bulgarian university students' metacognitive strategy awareness. Mauritius: Lambert Academic Publishing.

Graham, S., \& Harris, K. R. (2017). Reading and writing connections: How writing can build better readers (and vice versa). In Ng, C. \& Bartlett, B. (Eds.). Improving reading and reading engagement in the 21st century (pp. 333-350). Singapore: Springer.

Habibi, A., Wachyuni, S., \& Husni, N. (2017). Students' perception on writing problems: A survey at one Islamic university in Jambi. Ta'dib: Journal of Islamic education, $22(1), 96-108$.

Hood, S. (2005). What is evaluated and how in academic research writing? The copatterning of attitude and field. Australian Review of Applied Linguistics Series,19, 23-40.

Hood, S. (2008). Summary writing in academic contexts: Implicating meaning in processes of change. Linguistics and Education, 19(4), 351-365.

Hyland, K. (1998). Hedging in scientific research articles. Amsterdam: John Benjamins 
Hyland, K. (2007). Genre pedagogy: Language, literacy and L2 writing instruction. Journal of Second Language Writing, 16, 148-164.

Johns, M. (1985). Summary protocols of "unprepared" and "adept" university students: replications and distortions of the original. Language Learning, 35, 495-517.

Keck, C. (2006). The use of paraphrase in summary writing: a comparison of L1 and L2 writers. Journal of Second Language Writing, 15(4), 261-278.

Kim, S. A. (2001). Characteristics of EFL readers' summary writing: A study with Korean university students. Foreign Language Annals, 34(6), 569-581.

Kirkland, M. P., \& Sauders, M.A. (1991). Maximising student performance in summary writing: Managing cognitive load. TESOL Quarterly, 105-121.

Landauer, T.K., Foltz, P.W., \& Laham, D. (1998). Introduction to latent semantic analysis. Discourse Processes, 25, 259-284.

Lin, O. P., \& Maarof, N. (2013). Collaborative writing in summary writing: Student perceptions and problems. Procedia - Social and Behavioral Sciences, 90, 599606.

Martin, J. R. (1992). English text. Amsterdam: John Benjamins.

Pecorari, D. (2003). Good and original: Plagiarism and patchwriting in academic second-language writing. Journal of Second Language Writing, 12, 317-345.

Phillips Galloway, E., \& Uccelli, P. (2019). Beyond reading comprehension: Exploring the additional contribution of academic language skills to early adolescents' sourcebased writing. Reading and Writing: An Interdisciplinary Journal, 32(3), 729-759.

Rivard, L. P. (2001). Summary writing: A multi-grade study of French-immersion and Francophone secondary students. Language, Culture and Curriculum, 14, 171-186.

Shanahan, T. (2016). Relationships between reading and writing development. In MacArthur, C. A., Graham, S. \& Fitzgerald, J. (Eds.), Handbook of writing research (p. 194-207). The Guilford Press.

Shi, L. (2004). Textual borrowing in second-language writing. Written Communication, 21(2), 171-200.

Sung, Y., Liao, C., Chang, T., Chen, C., \& Chang, K. (2016). The effect of online summary assessment and feedback system on the summary writing on $6^{\text {th }}$ grades: the LSA-based technique. Computers and Education, 95, 1-18.

Swales, J. M. (1998). Textography: Towards a contextualization of written academic discourse. Research on Language and Social Interaction, 31(1), 109-121.

Swales, J. M., \& Feak, C. B. (2012). Academic writing for graduate students: Essential tasks and skills. Ann Arbor, MI: University of Michigan Press.

Uccelli, P., Barr, C. D., Dobbs, C. L., Phillips Galloway, E., Meneses, A., \& Sanchez, E. (2014). Core Academic language skills: An expanded operational construct and a novel instrument to chart school-relevant language proficiency in preadolescent and adolescent learners. Applied Psycholinguistics, 36(5), 1-30.

Vassileva, I. (2001). Commitment and detachment in English and Bulgarian academic writing. English for Specific Purposes, 20, 83-102. 
Wade-Stein, D., \& Kintsch, E. (2004). Summary street: interactive computer support for writing. Cognition and Instruction, 22(3), 333-362.

Yang, H. C. (2014). Toward a model of strategies and summary writing performance. Language Assessment Quarterly, 11(4), 403-431. 